\title{
Identificação dos elementos do trabalho padronizado na construção civil
}

\author{
Identification of the elements of standardized work in \\ construction
}

\section{Wanessa Roberta Fazinga Fernanda Aranha Saffaro}

\section{Resumo}

padronização é uma ferramenta de gestão voltada para a redução da
variabilidade no processo produtivo. No contexto do Sistema Toyota
de Produção (STP), a padronização é efetivada por meio do Trabalho
Padronizado (TP). Esta pesquisa tem por objetivo propor as especificações que devem compor um padrão para processos produtivos da construção civil a partir da adaptação do conceito de TP. Foi realizado um estudo de caso em canteiro de obra, na etapa executiva de estrutura de concreto armado, em uma construtora da cidade de Londrina/PR. Os elementos constituintes do TP puderam ser detectados no contexto da construção, porém algumas adaptações mostraram-se necessárias, resultando em especificações que contêm os três componentes do padrão citados na literatura: meta, restrições e método. A definição de metas mostrou-se válida por direcionar o estabelecimento do método. As especificações do método mostraram-se mais abrangentes do que aquelas citadas na literatura do STP, incluindo especificações relativas aos kits de recursos para cada pacote de trabalho e à forma de transporte e armazenagem dos mesmos nos postos de trabalho. Por outro lado, os resultados apontaram para um menor grau de detalhamento da rotina de operações padrão, tendo como foco o trabalho em equipe. Apesar das particularidades da construção civil, o TP mostrou-se como uma ferramenta potencialmente eficaz para a redução da variabilidade no processo produtivo.

Palavras-chave: Padrão. Padronização. Trabalho padronizado.

Wanessa Roberta Fazinga Programa de Pós-Graduação em Engenharia de Edificações e Saneamento

Universidade Estadual de Londrina Rod. Celso Garcia Cid, PR $445 \mathrm{Km}$ 380, Campus Universitário Caixa Postal 6001

Londrina - PR - Brasil CEP 86051-990 Tel.: (43) $3371-4470$ E-mail: wanessa@engetecprot.com.br

Fernanda Aranha Saffaro Programa de Pós-Graduação em Engenharia de Edificações e Saneamento Universidade Estadual de Londrina E-mail: saffaro@uel.br

Recebido em 22/10/11 Aceito em 06/08/12

\begin{abstract}
Standardization is a management tool aimed at reducing variability in the production process. In the context of the Toyota Production System (TPS), Standardized Work (SW) is the way standardization is put into practice. This research study aims to propose specifications to create a standard for production processes in construction through an adaptation of the SW concept. A case study was carried out in a construction site, located in Londrina/PR, during the execution of the reinforced concrete structure. The elements of the SW could be detected in the construction context, however some adjustments were necessary, resulting in specifications that contain the three components of the standard proposed in the literature: goal, constraints and method. The definition of goals has proved to be valid for guiding the establishment of the method. The

specifications related to the method were more comprehensive than those reported in TPS literature, including specifications concerned with the kit of resources for each work package and the way the kits should be moved and stored. By contrast, the standard operation routine was less detailed. It focused only on teamwork and not on individual routine throughout the day. Despite the peculiarities of the construction context, SW has proved to be a potentially effective tool for reducing variability in the production process.

Keywords: Standard. Standardization. Standardized work.
\end{abstract}




\section{Introdução}

A gestão da produção na construção civil é dificultada por algumas particularidades do setor, tais como produto de caráter único, organização temporária para a produção, grande diversidade de insumos e de fornecedores, e uso intensivo de mão de obra. Essas peculiaridades, aliadas a falhas de âmbito gerencial, como deficiências de planejamento, implicam dificuldade de obter resultados previsíveis e repetitivos, ou seja, um processo de produção estável. Pelo contrário, os empreendimentos da construção civil desenvolvem-se em um ambiente de alta incerteza, gerada pela presença da variabilidade.

Com o propósito de gerenciar de forma mais efetiva a produção no setor, algumas ações vêm sendo empreendidas, como, por exemplo, o emprego de ferramentas de gestão mais comumente utilizadas na indústria de manufatura. Entre essas ferramentas com potencial para combater a variabilidade, autores como Monden (1997), Spear e Bowen (1999), Liker (2005) e Imai (2005) apontam a padronização.

Esta pesquisa investiga a padronização na manufatura, especialmente no contexto do Sistema Toyota de Produção, em que a padronização é efetivada por meio do Trabalho Padronizado (TP), ou seja, uma forma específica de abordar a utilização de padrões. Uma das razões para a adoção do STP como referencial teórico é o entendimento do processo de produção segundo a concepção de processos e operações proposta por Shingo (1996), denominada Mecanismo da Função Produção (MFP). O MFP permite compreender a interação entre as diversas atividades que compõem um processo e, sobretudo, assumir a repercussão do fator tempo no desempenho da produção, gerenciando de forma mais efetiva a ocorrência da espera entre as atividades.

Esta pesquisa parte do pressuposto de que a adaptação do TP ao contexto da construção pode resultar no alcance repetido das características de qualidade, custo e prazo dos produtos da construção. O objetivo da pesquisa é propor especificações que devem compor um padrão para processos produtivos da construção civil a partir da adaptação do conceito de TP para esse contexto.

\section{Conceitos de padrão e padronização}

De acordo com o Productivity Press Development Team (2002), a padronização compreende o estabelecimento, a comunicação, a adesão e a melhoria de padrões. Um padrão, por sua vez, é uma especificação que fornece claras expectativas sobre um produto ou processo.

Imai (2005) refere-se ao padrão como um conjunto de regras e procedimentos que orientam a execução de tarefas, além de constituir um requisito básico para a melhoria do processo produtivo.

O conteúdo do padrão é discutido por Kondo (1991) e Campos (2004). Ambos ressaltam que um padrão deve explicitar uma meta para o trabalho e o método a ser empregado para alcançá-la. Kondo (1991) acrescenta o elemento restrição como componente do padrão, citando-o como um dos aspectos que devem ser obedecidos ao executar a tarefa.

No entanto, os referidos autores não apresentam esclarecimentos sobre a abrangência das metas, os aspectos que configuram uma restrição e os elementos que devem compor o método. Assim, buscou-se apoio em outras fontes da literatura para aprofundar o conhecimento sobre esses elementos, os quais são descritos a seguir.

\section{Meta}

Kondo (1991) menciona que o esclarecimento das metas é importante para incitar nos operários um senso de responsabilidade sobre o trabalho desenvolvido, contribuindo para que se sintam motivados a alcançar o objetivo proposto.

A identificação das metas envolve a priorização de critérios competitivos como custo, velocidade de entrega, confiabilidade na entrega e flexibilidade de volume produzido (BARROS NETO, 1999). Tendo em vista os critérios priorizados, o processo produtivo deve ser estruturado por meio do estabelecimento de metas específicas por todos os níveis organizacionais da empresa, até que cheguem ao nível operacional.

\section{Restrições}

Buscando esclarecer o conceito de restrição apresentado por Kondo (1991) como elemento do padrão, foram identificadas três abordagens diversas na literatura sobre gestão da produção.

Para Ritzman e Krajewski (2004), uma restrição é qualquer fator que limite o desempenho de um sistema produtivo e pode estar relacionada à capacidade da mão de obra, escassez de espaço ou de materiais (restrições físicas), queda na demanda de mercado ou políticas administrativas que tenham repercussão no fluxo de produção. 
As restrições relacionadas à capacidade de produção são também chamadas de gargalo, conforme relatam Goldratt e Cox (2002), sob a abordagem da teoria das restrições (TOC). Para estes autores, gargalo é o recurso ou processo mais lento do sistema de produção. Sendo assim, a capacidade do sistema permanecerá condicionada à velocidade de produção desse recurso.

Uma terceira abordagem para as restrições é denominada mecanismo de produção protegida (shielding production) e está fundamentada no sistema Last Planner de controle da produção (BALLARD; HOWELL, 1998). Segundo Ballard e Howell (1998), a análise de restrições envolve a identificação e remoção de obstáculos que impeçam ou dificultem a realização de uma tarefa. Ballard (2000) explica que esses obstáculos estão relacionados à disponibilidade dos inputs (KOSKELA, 1992), ou seja, informações de projeto ou de procedimentos de trabalho, conclusão de tarefas precedentes e disponibilidade dos recursos materiais, mão de obra e equipamentos. No Last Planner, somente tarefas cujas restrições foram removidas podem ter sua execução planejada para um horizonte de curto prazo.

Estabelecendo uma analogia entre as definições propostas pelos autores citados, é possível perceber que a abordagem de Ritzman e Krajewski (2004) é a mais abrangente, englobando inclusive a TOC. Há também divergências entre os autores. Enquanto Goldratt e Cox (2002) mencionam que as restrições estão atreladas à capacidade de produção (espaço disponível, quantidade de recursos, capacidade de equipamentos), para Ballard e Howell (1998) as restrições referem-se à existência de condições adequadas para a realização das tarefas, que podem ser dependentes dos processos à montante e da disponibilidade dos inputs para início do processo em questão.

Embora haja divergências entre os autores, há também um ponto em comum entre eles, uma vez que todos se referem às restrições como fatores que impõem limitações ao desempenho de um sistema, sendo essa, portanto, a definição adotada nesta pesquisa.

\section{Método}

A identificação dos elementos que compõem o método padronizado na construção é uma das investigações desta pesquisa. Porém, como ponto de partida, buscaram-se alguns autores que indicam elementos relevantes para a especificação de uma tarefa ou processo, embora não façam referência direta a um método padronizado.
Currie (1997) destaca aspectos que devem ser considerados para especificar tarefas que estejam sob intervenção em um processo de melhoria. Os principais aspectos são: o leiaute da área de trabalho, a quantidade de materiais, as especificações de qualidade do produto e momentos em que se deve efetuar inspeções. Ballard e Tommelein (1999) apresentam aspectos relevantes para especificar uma atividade visando à implantação de fluxo contínuo de produção, tais como:

(a) descrição de todas as atividades que compõem o processo;

(b) recursos mínimos;

(c) tamanho do lote de processo;

(d) tempo necessário para cumprir o lote de produção; e

(e) condições da área de trabalho em termos de espaço e acesso.

A partir dos elementos citados, assume-se que o método representa um conjunto de especificações sobre como executar uma tarefa, incluindo definições acerca dos recursos e ambiente de trabalho.

\section{Padronização no Sistema Toyota de Produção (STP)}

Uma vez esclarecidos os elementos conceituais do padrão, buscou-se um entendimento mais aprofundado do conceito de TP. Spear e Bowen (1999) ressaltam a importância de padrões claramente definidos no STP, descrevendo todas as atividades em termos de seu conteúdo, sequência, tempo e resultados esperados. Os mesmos autores mencionam, ainda, que o objetivo das especificações detalhadas é fazer com que qualquer desvio seja imediatamente percebido para que suas causas sejam tratadas.

Com base em Ohno (1997) e Liker e Meier (2007), entende-se que o TP consiste de uma especificação detalhada para as ações dos operários em um processo, de forma a produzir com um mínimo de perdas, em prazo adequado à demanda dos clientes e com baixo nível de estoque.

De acordo com Monden (1997) e o Lean Institut Brasil (2003), o TP é expresso por meio de três elementos:
(a) takt-time;
(b) sequência do trabalho (também denominada rotina de operações padrão); e

(c) estoque padrão de processo. 
Embora esses elementos do TP tenham sido especificamente formatados para o contexto do STP, é possível estabelecer semelhanças conceituais com os elementos do padrão citados por Kondo (1991), da seguinte forma:

(a) o takt-time está associado à meta a ser atingida, ou seja, produzir somente em concordância com a demanda de mercado;

(b) a rotina de operações é parte constituinte do método de trabalho;

(c) a limitação de uma quantidade padrão de estoque pode ser relacionada a uma restrição, ou seja, representa uma condicionante para a definição de como executar o trabalho no tempo atrelado à demanda, porém se respeitando um limite de itens em espera, aguardando para serem processados no posto de trabalho seguinte.

\section{Takt-time}

Para Alvarez e Antunes Junior (2001), o takt-time é entendido como o tempo que rege o fluxo de materiais em uma linha de produção e representa uma meta à qual o sistema de produção deve atender, ou seja, a cada intervalo definido pelo takt-time, uma unidade deve ser concluída na linha de produção. Tomando o tempo takt como meta, deve-se adequar o tempo de ciclo do processo, tornando-o igual ou ligeiramente menor que o takttime, para que a demanda seja atendida (LIKER; MEIER, 2007).

Martin e Bell (2011) relatam que em contextos em que as atividades apresentam longos tempos de ciclo, como na construção civil, há necessidade de subdividir o tempo de execução total do processo em períodos intermediários e menores, tomando-os como parâmetro para o monitoramento do avanço de cada atividade. Dessa forma, é possível tomar medidas corretivas quando o tempo de ciclo estiver abaixo ou acima do tempo takt definido.

Bulhões (2009) também comenta a adaptação do takt-time para a construção. Segundo a autora, os empreendimentos têm seu prazo fixado contratualmente com o cliente por meio de um cronograma, em que são especificadas as durações dos principais processos. A cada processo caberá um takt-time específico, cujo cálculo consiste na razão entre o tempo de produção disponível para o processo (definido no cronograma) e o número de unidades repetitivas (pavimento, apartamento).

\section{Sequência do trabalho}

Segundo Dennis (2008), a sequência do trabalho refere-se à ordem das tarefas que cada trabalhador deve executar dentro de um tempo determinado. Monden (1997) utiliza o termo "rotina de operações padrão" (ROP) e menciona que, quando o trabalho é executado por apenas um operário, essa rotina coincide com a sequência do processo. Em outras situações, vários operários são necessários em um mesmo posto de trabalho para cumprir um tempo de ciclo adequado ao takt-time. Nesse caso, cada um deles terá uma sequência de tarefas, que difere da sequência do processo, como mostra a Figura 1 . O processo consiste das operações de 1 a 8 , nesta ordem. Um operário executa as operações 1, 2, 7 e 8, enquanto outro é responsável pelas operações 3, 4, 5 e 6 .

Liker e Meier (2008) acrescentam que a simples adesão à ROP não significa produzir com eficiência. É necessário que sejam identificados os pontos-chave, definidos pelos autores como os pontos do trabalho que precisam ser executados com alto grau de precisão, a fim de evitar a ocorrência de defeitos. Os autores citam cinco categorias para os pontos-chave:

(a) segurança (evitar acidentes e lesões);

(b) qualidade (evitar erros que causem defeitos);

(c) produtividade (executar o trabalho no tempo especificado);

(d) custo (manter o custo especificado); e

(e) técnicas especiais (destreza).

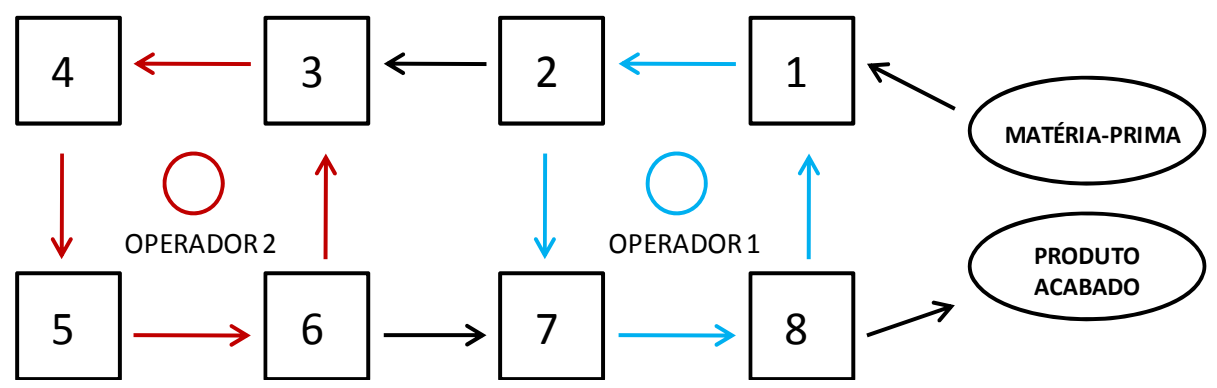

Figura 1 - Exemplo de rotina de operações

Fonte: adaptado de Productivity Press Development Team (2002). 


\section{Estoque padrão de processo}

Monden (1997) esclarece que o estoque padrão de processo refere-se à quantidade total de produtos parcialmente acabados que se acumulam ao longo da linha de produção, ou seja, os estoques intermediários que são necessariamente formados durante o processo produtivo. Pode também ser chamado de trabalho em progresso (Work-inprogress - WIP).

De acordo com o Lean Institut Brasil (2003), um dos propósitos do WIP é proteger os postos de trabalho subsequentes quando há algum problema que paralise a produção. Enquanto o problema pontual de um posto de trabalho é solucionado, os demais continuam produzindo. Entretanto, esse estoque deve ser mantido em quantidade controlada e estritamente necessária.

Outra contribuição importante do estabelecimento da quantidade padrão de estoque é que, cada vez que a quantidade aumenta ou diminui, fica evidente que algum descompasso está ocorrendo entre os postos de trabalho (WHITMORE, 2008). Dessa forma, o monitoramento da quantidade padrão de WIP contribui para a identificação de problemas na linha de produção e para a tomada de ações corretivas.

\section{Método de pesquisa}

A oportunidade para a realização do estudo ocorreu a partir da manifestação de insatisfação do gerente de produção de uma empresa construtora com relação à demora que as equipes de produção apresentavam para atingir o takt-time almejado sempre que um novo empreendimento era iniciado. Esse problema acarretava divergência em relação ao cronograma inicial do empreendimento e impunha um esforço posterior para a recuperação do desvio de prazo.

Motivada pelo problema apresentado, a equipe de pesquisadores vislumbrou a possibilidade de implantação do TP em um canteiro de obras de um edifício residencial de 26 pavimentos e selecionou o processo de produção de estruturas de concreto armado.

\section{Delineamento da pesquisa}

Com base em Yin (2001), a estratégia de pesquisa adotada foi o estudo de caso, por tratar-se do estudo de fenômenos reais contemporâneos sobre os quais a pesquisadora não exercia controle.

Para o início do estudo, realizou-se uma reunião com o engenheiro residente da obra, na qual foram apresentados os conceitos que embasaram a pesquisa, relativos à padronização e ao TP. Também foi apresentado um plano de trabalho para a realização da pesquisa, segundo quatro fases:
(a) compreensão;
(b) definição;
(c) implementação; e
(d) avaliação.

Para ilustrar o desenvolvimento delas ao longo do tempo, apresenta-se a Figura 2.

Após a reunião de apresentação, teve início o primeiro período de coleta de dados, denominado fase de compreensão, que teve como propósito a familiarização da pesquisadora com o processo construtivo adotado pela empresa e a identificação de informações relevantes para a elaboração do TP.

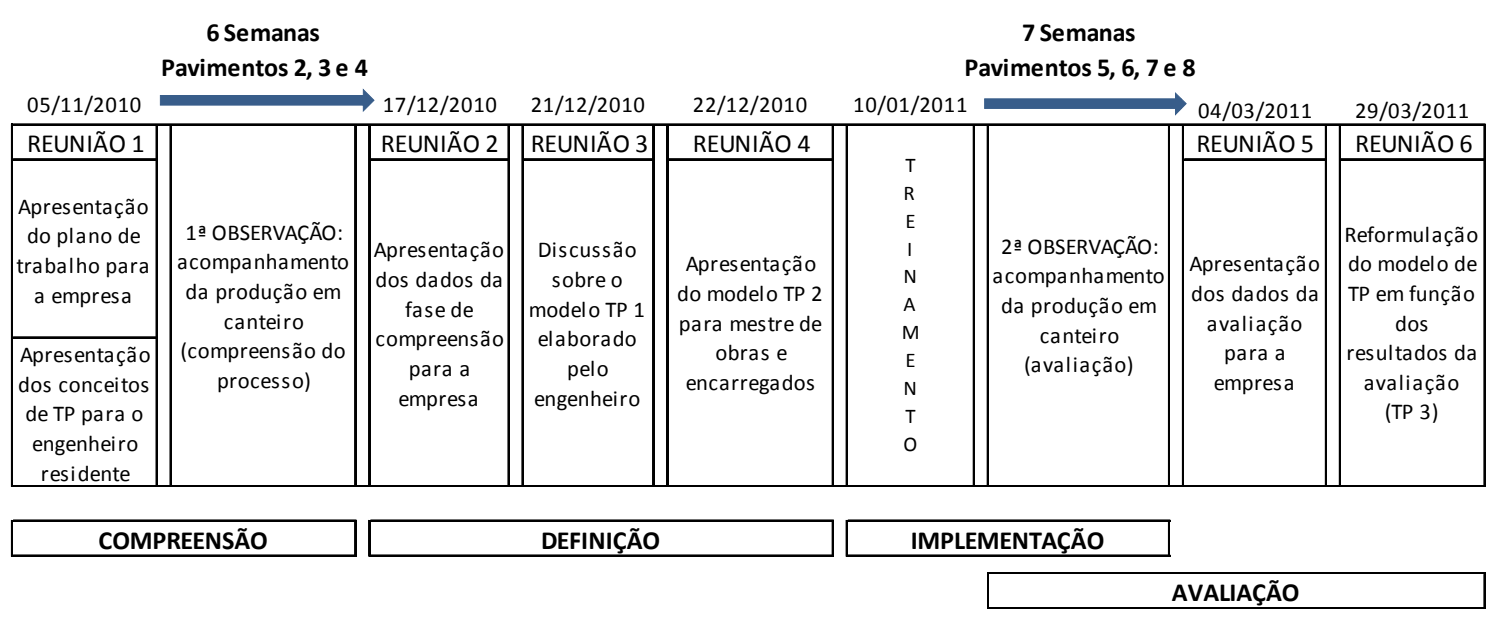

Figura 2 - Desenvolvimento temporal da pesquisa 
Efetuou-se uma análise dos projetos e documentos do Sistema de Gestão da Qualidade relacionados à produção da estrutura de concreto. Na sequência, partiu-se para o acompanhamento das atividades em canteiro por seis semanas consecutivas, correspondentes à execução do segundo, terceiro e quarto pavimentos. Além da observação da produção, eram efetuados questionamentos aos encarregados e aos operários, buscando identificar aspectos importantes para o desempenho do processo.

Os dados coletados nessa fase embasaram as discussões sobre as especificações do TP com o engenheiro da obra. A partir desses dados, ele elaborou o primeiro modelo de TP, denominado TP1. Esse modelo foi aprimorado após ser discutido com os encarregados de produção da construtora e da empreiteira $\mathrm{C}$, originando o documento TP2.

A comunicação do modelo TP2 à equipe de produção, por meio de um treinamento em sala de aula ministrado pelo engenheiro, configurou a fase de implementação. A partir do treinamento, teve início um segundo período de observação em canteiro, efetuado pela pesquisadora, durante 7 semanas consecutivas, correspondentes à execução do quinto ao oitavo pavimento. $\mathrm{Na}$ fase de avaliação, procurou-se verificar a repercussão dos elementos até então definidos no TP e confirmar se eles tinham o potencial de reduzir a variabilidade da produção.

A partir dos dados da fase de avaliação e após duas reuniões com o engenheiro e encarregados de produção, efetuou-se a reformulação do modelo de TP, dando origem ao documento TP3. Este modelo não foi implantado devido a dificuldades da empresa quanto à disponibilidade de tempo para intervenções na produção, porém contribuiu para a análise conceitual da adaptação do TP para o contexto da construção.

\section{Estudo de caso}

\section{Descrição do processo construtivo}

A produção de estrutura contava com um equipamento grua para transporte vertical e horizontal, que era utilizado exclusivamente para essa etapa da obra. As lajes eram do tipo nervuradas e protendidas. Utilizava-se sistema de escoramento metálico (Figura 3), sobre o qual era executado um assoalho de chapas de madeira compensada que apoiavam as formas plásticas para a laje (Figura 4).

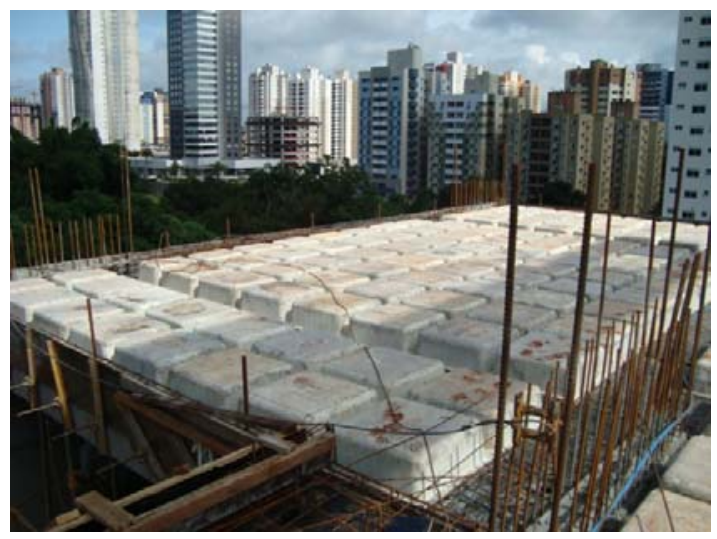

Figura 3 - Sistema de escoramento

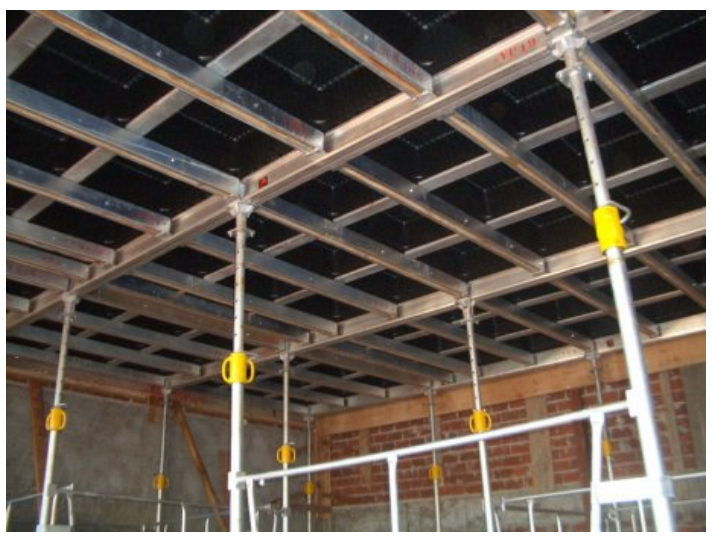

Figura 4 - Formas plásticas distribuídas 
A empresa adotava pré-vigas de concreto, produzidas no próprio canteiro de obras. Na central de produção, instalada no nível do primeiro subsolo, as pré-vigas eram concretadas até aproximadamente metade da altura de sua seção transversal. Após o posicionamento da viga na estrutura do pavimento, o restante de sua altura era complementado com as formas de borda e concretada juntamente com a laje.

Cada laje de pavimento tipo foi dividida em duas etapas de execução, chamadas de Fases 1 e 2, como indicado na Figura 5. Para execução em conformidade com o planejamento de longo prazo, havia necessidade de concluir a estrutura de um pavimento a cada sete dias trabalhados. Para tanto, a equipe de produção dividia-se entre as fases da laje, executando-as de forma paralela. Porém, a Fase 2 deveria sempre se iniciar três dias após a Fase 1, para que alguns materiais pudessem ser compartilhados.

\section{Desenvolvimento do estudo de caso}

\section{Fase de compreensão}

A análise dos projetos e documentos permitiu identificar três procedimentos documentados no SGQ referentes à produção de estruturas: armação, formas e concretagem. Esses documentos enfatizavam aspectos técnicos de execução e os pontos de inspeção ao longo do processo relacionados, principalmente, a prumo, nivelamento e esquadro dos elementos estruturais, evidenciando apenas metas de produção relacionadas às características do produto final. Não constavam informações que evidenciassem a preocupação com o controle de prazo para os ciclos de concretagens, ainda que esse aspecto fosse bastante valorizado pela empresa, que se posiciona no mercado como cumpridora dos prazos de entrega.
Havia, também, uma planilha de programação de serviços utilizada pelo engenheiro para orientar a produção da estrutura entre os sete dias do ciclo para cada pavimento. As orientações constantes nessa planilha eram pouco detalhadas, consistindo apenas de um sequenciamento das tarefas, não abordando restrições, compartilhamento de recursos, distribuição de funcionários entre atividades ou as operações de transporte e armazenagem.

Partindo para a observação em canteiro, buscou-se verificar se as informações constantes nos documentos verificados estavam sendo utilizadas pela equipe. Relatos dos operários evidenciaram que eles estavam conscientes quanto ao ciclo de sete dias para as concretagens e que esse prazo era bastante valorizado pela empresa. O prazo de sete dias foi, então, associado ao takt-time, pois foi tomado como a taxa de demanda para a execução das lajes. Tendo em vista que o TP seria formulado com o propósito de adequar a produção ao takttime, esse prazo foi também considerado como o elemento meta do padrão.

Foi possível perceber dificuldades de organização da equipe com reflexos no tempo de execução das tarefas. Inicialmente, foram identificadas diversas atividades que não estavam relacionadas na planilha de programação de serviços, tais como desforma dos pilares e das lajes e posicionamento do sistema de proteção da periferia dos pavimentos. Considera-se que a omissão dessas atividades na distribuição dos serviços prejudica o dimensionamento do volume de trabalho diário, bem como a previsão sobre a utilização da grua entre as fases da laje. Fica evidente que o conhecimento detalhado do conteúdo do trabalho é ponto de partida para a definição de outros elementos, tais como a sequência de execução, o compartilhamento de recursos e a capacidade de produção da equipe.

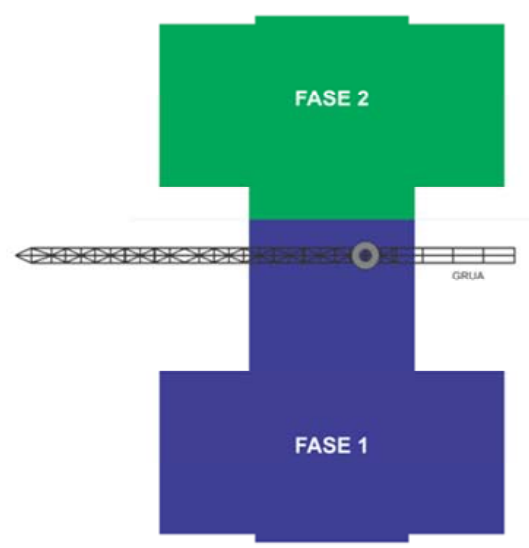

Figura 5 - Divisão do pavimento-tipo em duas fases de execução 
Foram também percebidas variações na execução das operações de transporte de materiais, especialmente aquelas referentes a itens numerosos, como escoras, tensores de formas e gastalhos. Os operários repetiam várias vezes o trajeto entre pavimentos, transportando essas peças manualmente, em pequenas quantidades por vez. Em outras ocasiões, os mesmos itens eram transportados pela grua. Em função dessas variações, foram constatadas oscilações na quantidade de operários que trabalhavam nas operações de processamento, pois eles se deslocavam constantemente do posto de trabalho para efetuar transportes, ocasionando interrupções no fluxo de produção.

Outra constatação foi que, quando os pilares eram desformados, os painéis de forma eram levados com a grua para armazenagem no pavimento térreo, até sua próxima utilização. Esse transporte foi considerado desnecessário, tendo em vista a possibilidade de armazenagem dessas formas no próprio pavimento.

Tais circunstâncias mostram que as definições sobre transporte e armazenagem repercutiam de forma relevante no desempenho da produção e deveriam ser analisadas na elaboração do TP. Algumas dessas operações poderiam ser eliminadas e outras melhoradas, contando com o auxílio da grua para sua execução.

A utilização da grua e, especialmente, seu uso compartilhado entre as duas fases da laje mostraram-se um aspecto bastante decisivo para o alcance da meta de prazo, o que pode estar associado ao que Kondo (1991) denomina de restrição, na medida em que, quando em uma das fases da laje estiver sendo realizada uma atividade que necessita da grua, a outra fase deverá contemplar serviços que dispensem sua utilização. Ou seja, a utilização da grua por uma das fases restringe os serviços que podem ser executados na outra fase. Os principais serviços que exigiam o uso da grua nos pavimentos eram o

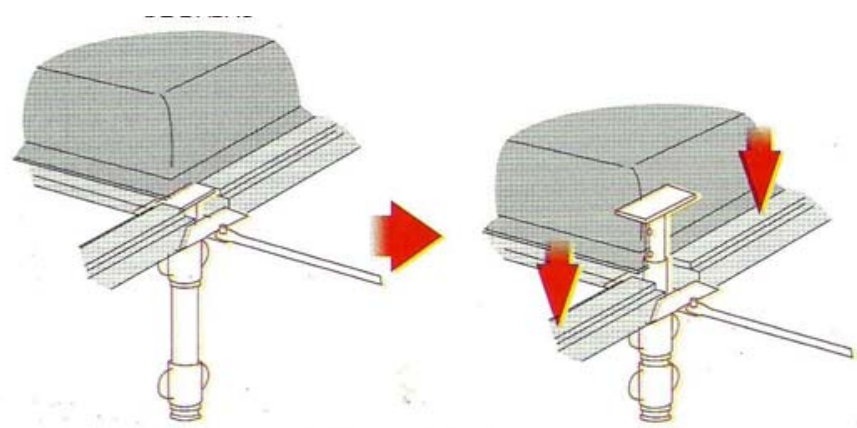

Figura 6 - Representação do encaixe das formas plásticas nas escoras posicionamento de pré-vigas e a movimentação de formas de pilares, que, devido a sua dimensão e peso, não podiam ser montados ou desformados manualmente. A grua era necessária também para realizar a concretagem de pré-vigas no pátio de produção. Assim, nos períodos da concretagem a grua deixava de atender à produção nos pavimentos da estrutura.

Dessa forma, o uso compartilhado da grua tem relação com o conceito de restrições físicas apresentado por Ritzman e Krajewski (2004), que se refere à capacidade do equipamento.

Outra dificuldade importante observada em canteiro refere-se à montagem do sistema de escoramento. O sistema exige precisão no posicionamento das escoras, uma vez que a cabeça da escora deve coincidir com a região de encaixe de quatro formas plásticas e com um recorte no assoalho, para que seja possível desformar a laje sem retirar as escoras (sistema drop-head - Figura 6). Sendo assim, erros no posicionamento das escoras impedem o encaixe das formas.

Apesar de haver um projeto orientativo para a montagem do escoramento, observou-se a recorrência de erros de posicionamento de escoras e retrabalho nessa operação. A montagem era iniciada pelas bordas da laje. Para o posicionamento da primeira linha de escoras era utilizada uma galga entre a face da viga periférica da laje e o alinhamento da primeira fila de escoras, seguindo a medida determinada no projeto. A distância entre as demais linhas de escoras em relação à primeira era determinada pelo comprimento das vigas metálicas de travamento entre elas, portanto, sem variações significativas. Assim, entende-se que a precisão no posicionamento das escoras é dependente da operação de marcação da galga (Figura 7), sendo essa operação associada a um ponto-chave com repercussão na qualidade, como descrito por Liker e Meier (2008). 


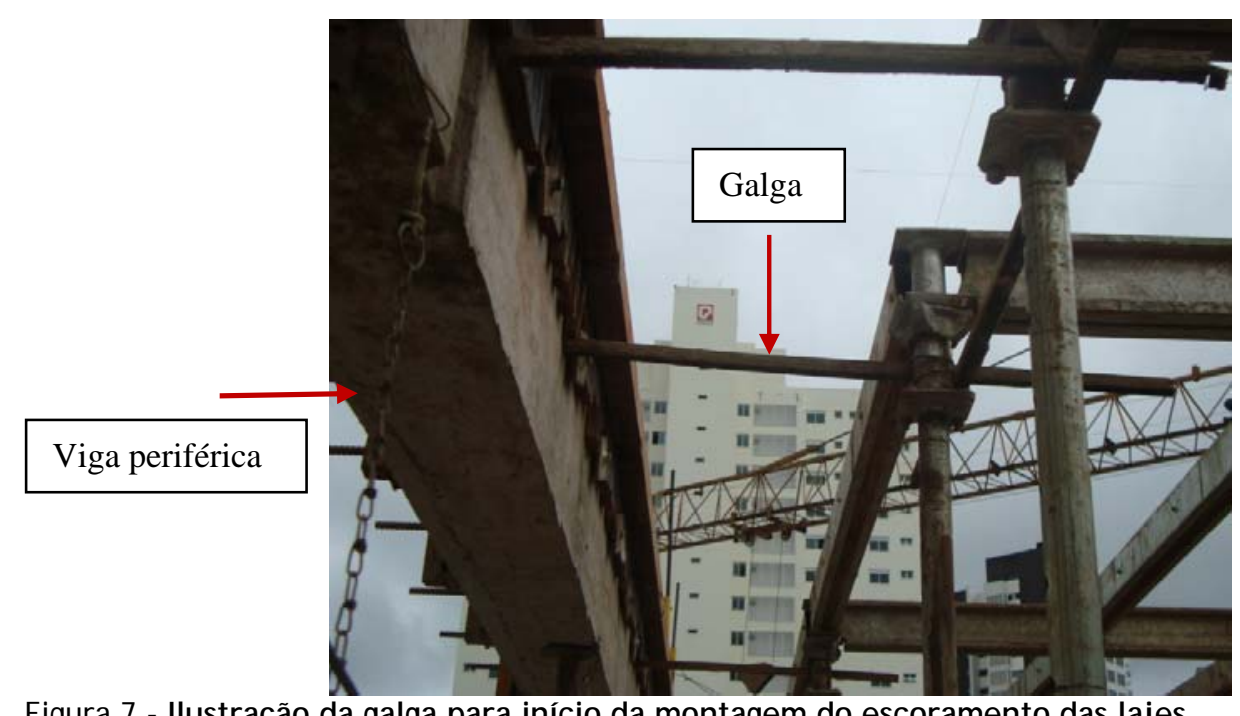

Figura 7 - llustração da galga para início da montagem do escoramento das lajes

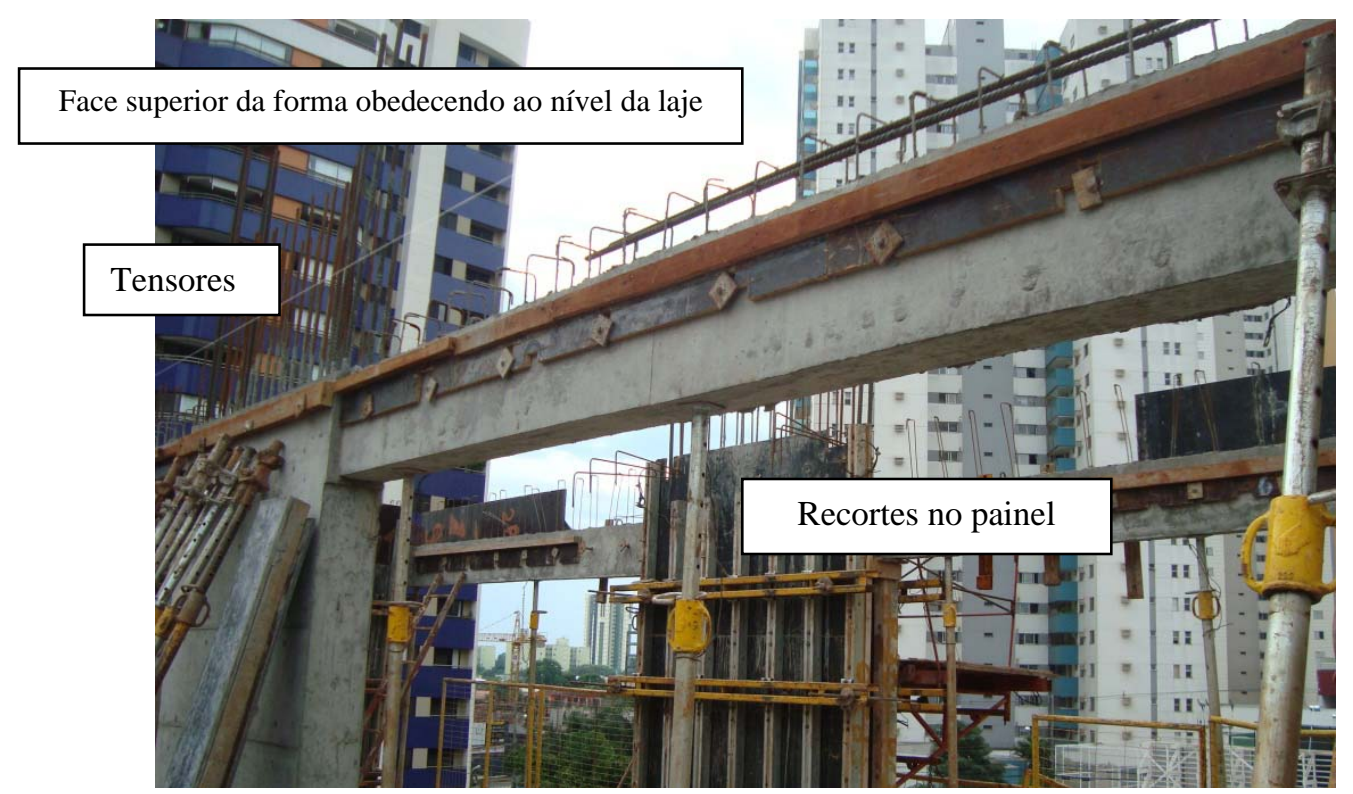

Figura 8 - Vista dos painéis de formas de bordas

A montagem das formas de bordas das pré-vigas também foi considerada uma atividade de baixa produtividade. O painel da forma deveria ser apoiado nos tensores metálicos de travamento e, para tanto, a forma continha recortes que possibilitavam o encaixe nos tensores, como mostra a Figura 8. A dificuldade nesse serviço estava associada ao reaproveitamento dos painéis entre os pavimentos, pois o painel recortado conforme a disposição de tensores em uma viga deveria ser reutilizado no pavimento superior, na viga de mesma denominação.

No entanto, os painéis não eram identificados, e durante a desforma as peças misturavam-se, dificultando o encaixe no pavimento superior. Após várias tentativas de encaixe sem sucesso, os operários acabavam recortando o painel uma vez mais, o que anulava a possibilidade de uma futura utilização.

Desse modo, a identificação dos painéis de forma, de acordo com a viga para a qual se destinam, foi considerada um ponto-chave com repercussões em dois fatores:

(a) na produtividade, uma vez que afetava o tempo requerido para essa tarefa; e

(b) no custo, pois influenciava o número de utilizações possíveis para as peças de forma.

Buscou-se, também, identificar outros aspectos relevantes para o estabelecimento do método. Sobre a questão da alocação dos operários, constatou-se que algumas atividades eram 
executadas sempre pelos mesmos operários, que trabalhavam em conjunto, como no posicionamento das pré-vigas, em que os quatro operários necessários para a tarefa foram os mesmos em todos os ciclos observados.

Considera-se que a permanência dos operários na mesma tarefa tem como aspecto favorável o conhecimento aprofundado adquirido sobre a tarefa, inclusive quanto aos pontos-chave e às restrições.

No entanto, questionamentos feitos aos operários evidenciaram que eles eram contrários à designação específica de tarefas, pois consideravam mais importante a interação entre todos os membros da equipe, criando um ambiente em que todos se ajudavam, independentemente de sua função específica. Esse aspecto, inerente ao trabalho em equipe, levantou dúvidas quanto ao estabelecimento da rotina de operações padrão. A possibilidade de os operários alternarem-se na execução de uma mesma tarefa dificulta o estabelecimento de uma rotina de operações com foco no indivíduo, como preconiza a literatura referente ao STP.

Encerrando a fase de compreensão, procurou-se identificar definições relativas ao trabalho em progresso (WIP), que foi evidenciado na produção de pré-vigas. Cada vez que um lote de pré-vigas era concretado no pátio de produção, as peças eram retiradas das formas e armazenadas no pavimento térreo, liberando as formas para a próxima utilização. Esse estoque deveria ter sempre a quantidade de vigas necessárias para a execução de um pavimento da estrutura, configurando uma quantidade padrão de WIP para as pré-vigas.

O projeto estrutural determinava que as pré-vigas somente podiam ser utilizadas após sete dias de sua concretagem. Essa determinação foi considerada como uma restrição, uma vez que a regularidade na concretagem das vigas seria importante para o fluxo dos serviços nos pavimentos, podendo representar um bloqueio em sua continuidade caso faltassem vigas com idade adequada para uso na estrutura. Sendo assim, a definição do WIP padrão para as pré-vigas representa uma maneira de atenuar o efeito dessa restrição sobre o ritmo de produção da estrutura.

Constatou-se que houve ciclos em que, devido a atrasos na produção de pré-vigas, o estoque intermediário foi totalmente consumido, fazendo com que a produção no pavimento ficasse condicionada ao ritmo em que as pré-vigas eram liberadas para uso. Esse fato reforça a consideração sobre a idade de utilização das prévigas como uma restrição.

\section{Fase de definição}

Iniciando-se esta fase fez-se uma discriminação detalhada das atividades que compunham o processo, esclarecendo o conteúdo do trabalho. O sequenciamento dessas atividades (Figura 9) foi estabelecido de acordo com o que preconizavam os procedimentos do SGQ, acrescentando alguns serviços identificados pela observação em canteiro que não estavam anteriormente relacionados nesses documentos (em destaque na Figura 9).

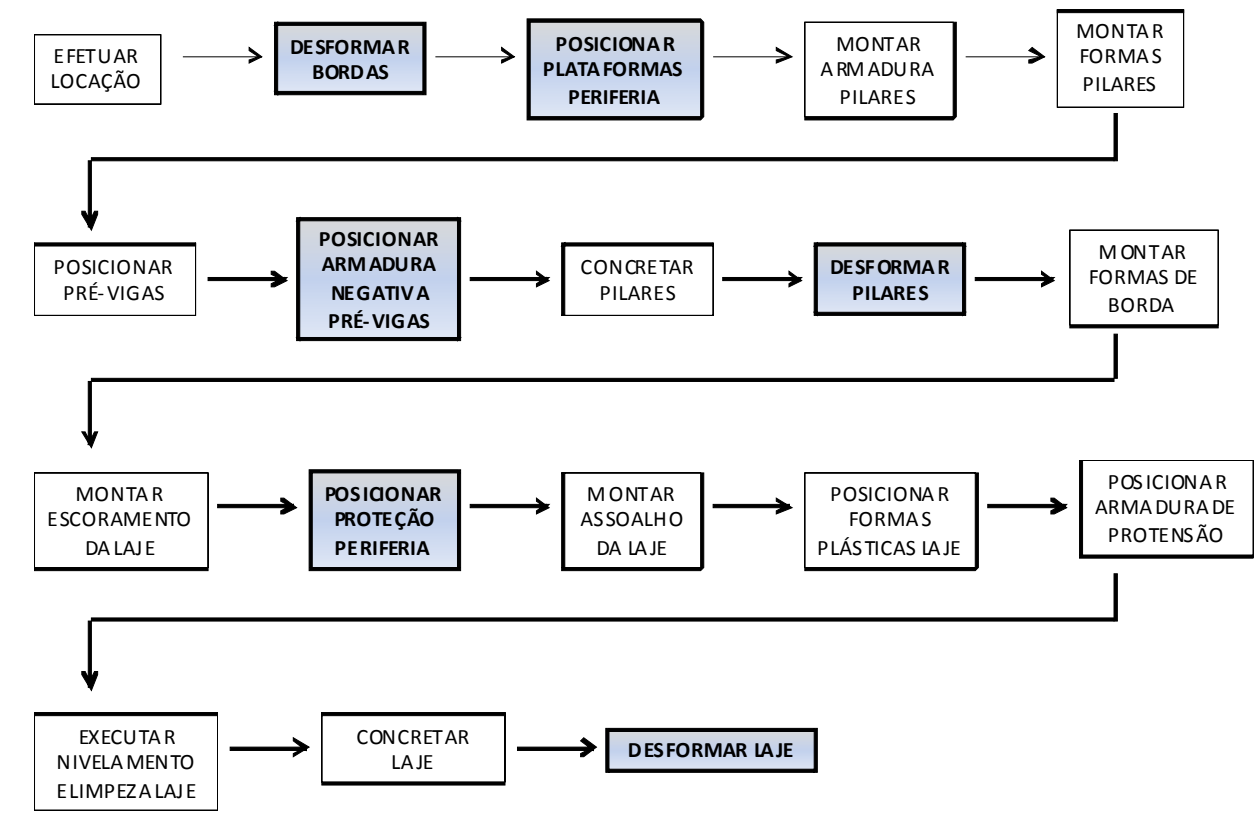

Figura 9 - Delineamento do processo de produção da estrutura 
Nota-se que as atividades discriminadas referem-se às operações de processamento, não havendo detalhamento das atividades de transporte $\mathrm{e}$ inspeção nessa fase da pesquisa.

Também foram relatadas ao engenheiro as dificuldades enfrentadas pela equipe para a execução das tarefas, além de destacar a implicação que o compartilhamento da grua tinha no fluxo de produção. A partir das discussões dos dados coletados, ficou sob a responsabilidade do engenheiro decidir sobre as especificações que considerasse importantes e elaborar a primeira versão da planilha de trabalho padronizado, denominada modelo TP1.

No primeiro campo da planilha, estava a indicação do dia correspondente do ciclo, de um a sete. No segundo campo, a descrição das atividades a serem desenvolvidas no dia correspondente, ou seja, os pacotes de trabalho relacionados de forma sequencial (Figura 9). Pacotes de trabalho, segundo Coelho (2003), correspondem à quantidade de trabalho definida por três elementos essenciais (ação, elemento e local), cuja terminalidade deve ser facilmente identificada. Por exemplo, montagem de escoramento do lote A1 da laje no terceiro pavimento.

No modelo TP1, optou-se por não fixar o tamanho dos pacotes a serem concluídos, mas apenas estipular uma faixa de valores. Como exemplo, pode-se citar a execução de formas de pilares, que deveria ficar entre 5 e 9 pilares, no primeiro dia da fase 1. Segundo o engenheiro, essa foi uma maneira de evitar a rigidez nas definições do método. No entanto, considera-se que tal variação não estava de acordo com o conceito de pacote de trabalho adotado na pesquisa, que visava a aumentar a precisão na designação de tarefas, evitando gerar dúvidas para a equipe de produção sobre o momento de encerrar um pacote e iniciar o seguinte. Além disso, as unidades pendentes se acumulariam aos pacotes de trabalho do dia seguinte, interferindo no tempo necessário para sua conclusão.

Cabe ressaltar que, para a distribuição dos pacotes de trabalho ao longo dos dias, todas as restrições foram levadas em consideração, embora não tenham sido registradas na documentação do TP.
O terceiro campo da planilha indicava o número de operários alocados em cada pacote de trabalho, de acordo com o dia do ciclo e com a fase da laje. Após a discussão do modelo TP1 com os encarregados de produção, foram feitas duas complementações, que resultaram no modelo TP2:

(a) inclusão das definições sobre armazenagem de materiais no próprio pavimento de trabalho; e

(b) elaboração de uma rotina de operações para a grua.

A rotina da grua tratava-se da especificação das atividades diárias a serem seguidas pelo operador da grua, servindo as fases 1 e 2 da laje para o cumprimento dos pacotes de trabalho designados para cada dia do ciclo de concretagens.

\section{Fase de implementação}

O treinamento utilizando o modelo TP2 enfatizou que a elaboração do TP representava a tentativa da empresa de conduzir a produção em direção ao cumprimento sistemático do ciclo de sete dias para os pavimentos, ou seja, a meta foi explicitada para a equipe. Foi feita uma explicação sobre a sequência dos pacotes de trabalho, destacando as restrições e os pontos-chave identificados.

Quanto ao transporte e armazenagem dos insumos, não houve definições rígidas sobre como executálos, somente orientações para maior organização dos materiais na área de trabalho e para a facilitação das operações de transporte. Sobre as formas de pilares, houve a recomendação de que elas não fossem mais transportadas até 0 pavimento térreo, mas sim dispostas nas áreas do próprio pavimento, indicadas no TP2. Após o treinamento, a documentação do TP foi disponibilizada no pavimento de trabalho.

\section{Fase de avaliação}

Durante o segundo período de observações, verificou-se que a equipe de produção não consultava a documentação do TP2 (Quadro 1) para orientar suas atividades diárias. Porém, os encarregados da produção argumentavam que tinham conhecimento sobre a sequência das atividades e os prazos para conclusão delas. No entanto, ocorriam desvios em relação ao cumprimento dos pacotes de trabalho diários, número de operários em cada pacote e em relação ao takt-time. 


\begin{tabular}{|c|c|c|c|c|c|c|c|}
\hline \multicolumn{4}{|c|}{ PRIMEIRA FASE DA LAJE } & \multicolumn{4}{|c|}{ SEGUNDA FASE DA LAJE } \\
\hline Dia & $\begin{array}{l}\text { Pacote de } \\
\text { trabalho }\end{array}$ & $\begin{array}{c}\text { Detalhamento do pacote } \\
\text { de trabalho }\end{array}$ & $\begin{array}{c}\mathrm{N}^{\circ} \text { de } \\
\text { operários }\end{array}$ & Dia & $\begin{array}{l}\text { Pacote de } \\
\text { trabalho }\end{array}$ & $\begin{array}{c}\text { Detalhamento do } \\
\text { pacote de } \\
\text { trabalho } \\
\end{array}$ & $\begin{array}{c}\mathrm{N}^{\circ} \text { de } \\
\text { operários }\end{array}$ \\
\hline \multirow{7}{*}{$\begin{array}{l}. \pi \\
: 7 \\
0 \\
0\end{array}$} & $\begin{array}{l}\text { Locação de } 18 \\
\text { pilares }\end{array}$ & $\begin{array}{l}\text { - Locação gastalhos } \\
\text { (1 operário + } \\
\text { encarregado) } \\
\text { - Fixação bases de } \\
\text { escoras para pilares } \\
\text { (1 operário) } \\
\end{array}$ & \multirow{7}{*}{6} & \multirow{7}{*}{$\begin{array}{l}\text { :7 } \\
\text { in }\end{array}$} & $\begin{array}{l}\text { Desforma } \\
\text { laje do } \\
\text { pavimento } \\
\text { inferior }\end{array}$ & & \multirow{7}{*}{11} \\
\hline & $\begin{array}{l}\text { Desforma } \\
\text { bordas }\end{array}$ & $\begin{array}{l}\text { - Desforma bordas } \\
\text { (4 operários) }\end{array}$ & & & $\begin{array}{l}\text { Montagem e } \\
\text { escora- } \\
\text { mento BKS } \\
\text { (L3-L4-L5) }\end{array}$ & $\begin{array}{l}\text { - Montagem } \\
\text { cimbramento } \\
\text { (4 operários) }\end{array}$ & \\
\hline & $\begin{array}{l}\text { Posicionamento } \\
\text { plataformas de } \\
\text { periferia }\end{array}$ & $\begin{array}{l}\text { - Colocação plataformas } \\
\text { (4 operários) }\end{array}$ & & & $\begin{array}{l}\text { Assoalho e } \\
\text { formas } \\
\text { plásticas }\end{array}$ & $\begin{array}{l}\text { - Montagem } \\
\text { assoalho e } \\
\text { distribuição } \\
\text { formas plásticas } \\
\text { (4 operários) } \\
\text { - Transporte } \\
\text { peças do } \\
\text { pavimento } \\
\text { inferior (3 } \\
\text { operários) - } \\
\text { - } 1 \text { operário da } \\
\text { produção de } \\
\text { pré-vigas vai } \\
\text { para o } \\
\text { pavimento }\end{array}$ & \\
\hline & $\begin{array}{l}\text { Montagem } \\
\text { armadura de } 18 \\
\text { pilares }\end{array}$ & Armadores & & & $\begin{array}{l}\text { Armadura } \\
\text { laje }\end{array}$ & $\begin{array}{l}\text { - Armadores - } \\
\text { após } 12 \mathrm{~h} 00\end{array}$ & \\
\hline & $\begin{array}{l}\text { Montagem } \\
\text { formas de } \\
\text { pilares (5 a } 9 \\
\text { un.) }\end{array}$ & $\begin{array}{l}\text { - Colocação formas e } \\
\text { agulhas (2 operários) } \\
\text { - Colocação escoras + } \\
\text { prumo + esquadro } \\
\text { (2 operários) } \\
\text { - Limpeza e aplicação } \\
\text { desmoldante } \\
\text { (2 operários) }\end{array}$ & & & & & \\
\hline & $\begin{array}{l}\text { Posicionamento } \\
\text { pré-vigas ( } 4 \text { a } 9 \\
\text { un.) }\end{array}$ & $\begin{array}{l}\text { - Posicionamento cabeça } \\
\text { dos pilares ( } 2 \text { operários) } \\
\text { - Posicionando escoras } \\
\text { ( } 2 \text { operários) } \\
\text { - Aferição esquadro } \\
\text { (2 operários) }\end{array}$ & & & & & \\
\hline & $\begin{array}{l}\text { Desforma laje } \\
\text { do pavimento } \\
\text { inferior }\end{array}$ & & & & & & \\
\hline
\end{tabular}

Quadro 1 - Visualização parcial da planilha do modelo TP2

As recomendações do treinamento sobre organização da área de trabalho e transporte de materiais tiveram repercussão positiva. Ao efetuar a desforma de lajes e pilares, os materiais passaram a ser mais bem organizados no pavimento (Figura 10). Peças pequenas, como gastalhos e tensores, deixaram de ser transportadas manualmente e passaram a ser armazenadas em caixotes de madeira transportados pela grua, mais rapidamente do que o observado na fase de compreensão.

A melhoria quanto à organização dos materiais fez com que o pavimento ficasse mais limpo e desimpedido, o que permitiu a utilização mais frequente de carrinhos de transporte horizontal de materiais que estavam disponíveis na obra, ajudando a equipe a realizar os transportes em maior volume, com menor esforço físico e mais segurança (Figura 11). 


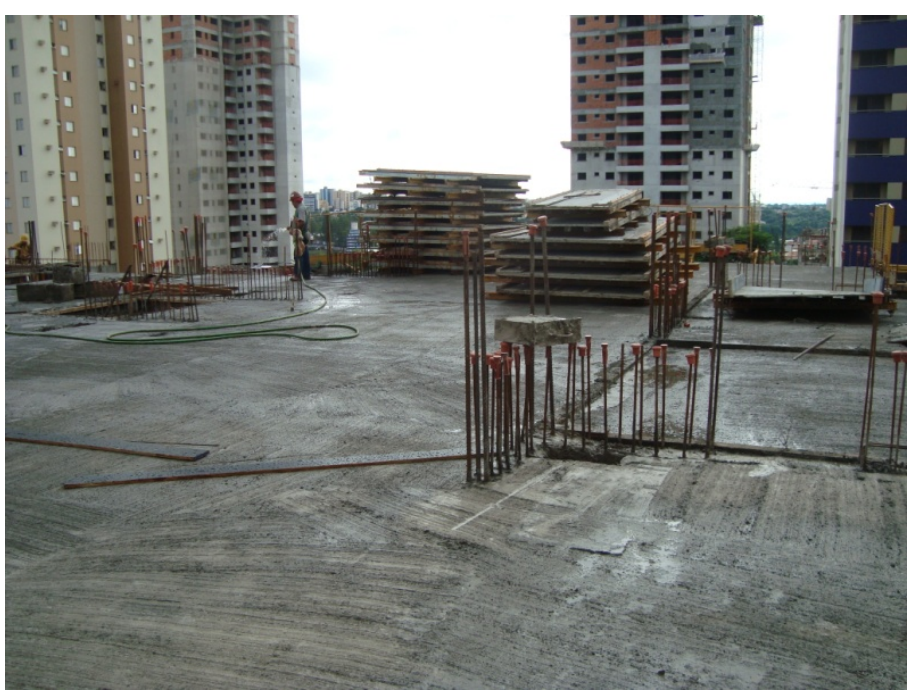

Figura 10 - Limpeza na área de trabalho e armazenagem de formas no pavimento

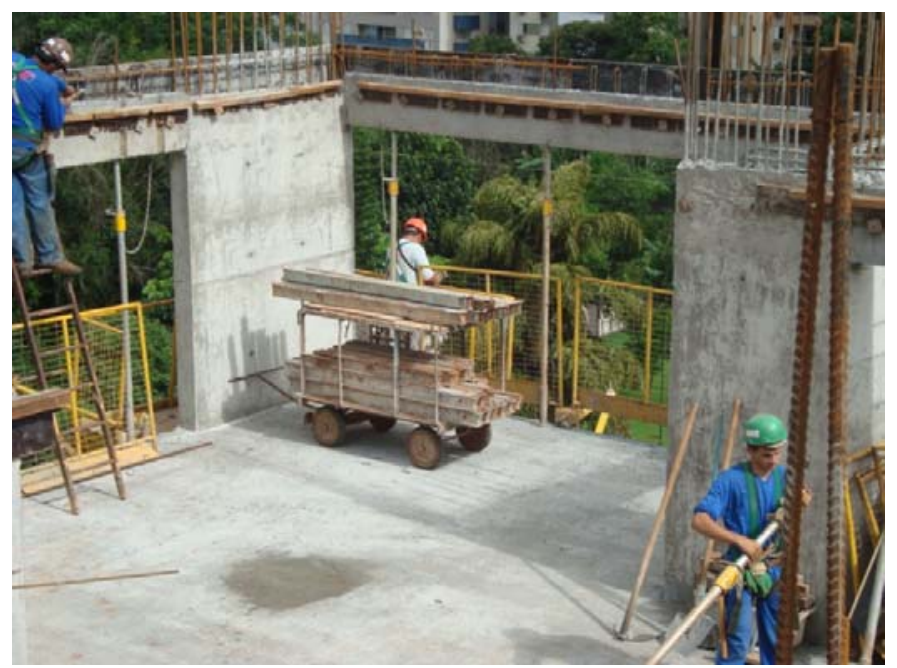

Figura 11 - Utilização de carrinhos para transporte em área de trabalho organizada

Apesar das melhorias relatadas, ainda foram observadas dificuldades quanto à disponibilidade dos recursos. Isso não significa que estes não estivessem disponíveis na obra, mas sim que não eram levados aos postos de trabalho de maneira sistemática e no momento necessário. Operários continuavam a deslocar-se do posto de trabalho em busca de ferramentas ou materiais para a realização da tarefa.

Houve, também, adesão aos pontos-chave constantes no TP2, obtendo resultados positivos, especialmente na execução das formas de borda. Os operários efetuaram a identificação das peças de forma conforme as vigas em que seriam utilizadas e passaram a retirar os painéis do pavimento inferior apenas no momento de sua próxima utilização, evitando a armazenagem provisória, quando os painéis poderiam misturar-se de forma desordenada. Como resultado, a execução dessas formas passou a ser concluída dentro do período de um dia de trabalho, como determinava o modelo TP2. A obediência à galga de posicionamento do escoramento das lajes evitou a ocorrência de erros nessa atividade nos quatro pavimentos observados na fase de avaliação.

Ao encerrar a fase de avaliação, procedeu-se a uma síntese dos dados coletados durante todo o período do estudo, desde o segundo pavimento até o oitavo, evidenciando que nenhum dos ciclos foi concluído em conformidade com o takt-time de sete dias, como mostra o Quadro 2. Embora o objetivo desta pesquisa não esteja associado à análise da mudança ocorrida com a implementação do modelo de TP, cabe ressaltar que nos pavimentos executados após a implementação houve convergência do tempo de ciclo em torno dos 10 dias. Contudo, não se pode afirmar que esse resultado seja decorrente da utilização do TP, 
tendo em vista que poucas das especificações contidas nele tiveram adesão da equipe de produção.

A fase de avaliação provocou nova reflexão acerca dos elementos do TP. O modelo foi aprimorado e deu origem ao TP3, ilustrado no Quadro 3. As alterações contidas no TP3 são descritas na sequência.

O tamanho dos pacotes de trabalho foi claramente definido, eliminando a faixa de variação anteriormente estabelecida. Houve também a definição da sequência em que os componentes de cada pacote deveriam ser executados, havendo, portanto, uma ordem específica para montagem e concretagem de pilares, para posicionamento de pré-vigas e montagem do escoramento de lajes. Essa sequência levou em consideração a redução de deslocamentos da grua e dos operários, a melhoria da terminalidade dos serviços e a possibilidade de iniciar-se a execução de um pacote de trabalho mesmo antes da conclusão total do pacote anterior, caso fosse necessário.
Outra definição acrescentada no TP3 foi o estabelecimento de um kit de recursos, relacionado a cada pacote de trabalho. O kit representaria um elemento do método padronizado, justificado pela necessidade de melhor gerenciar a disponibilidade de recursos e evitar esperas ou deslocamentos dos operários do posto de trabalho para buscá-los, acarretando variabilidade na duração do pacote.

Como já mencionado, o TP3 não foi implantado, porém uma reflexão sobre seu conteúdo permitiu a discriminação de um conjunto de especificações importantes para o gerenciamento da produção na construção.

\section{Elementos do TP para Construção Civil}

As especificações identificadas como importantes para a redução da variabilidade da produção na construção podem refletir os elementos conceituais genéricos do padrão: meta, restrições e método. Por esse motivo, optou-se por apresentar o conteúdo do TP de forma categorizada segundo esses elementos, conforme o Quadro 4.

\begin{tabular}{|c|c|c|}
\hline $\begin{array}{r}\text { Pavimento } \\
\text { (Fase 1+2) }\end{array}$ & $\begin{array}{l}\text { Tempo de ciclo } \\
\text { (dias úteis) }\end{array}$ & \\
\hline 2 & 17 & \multirow{3}{*}{ Fase de compreensão } \\
\hline 3 & 16 & \\
\hline 4 & 13 & \\
\hline 5 & 10 & \multirow{4}{*}{$\begin{array}{l}\text { Fases de } \\
\text { implementação e } \\
\text { avaliação }\end{array}$} \\
\hline 6 & 10 & \\
\hline 7 & 10 & \\
\hline 8 & 11 & \\
\hline
\end{tabular}

Quadro 2 - Duração dos ciclos de execução dos pavimentos

40 Fazinga, W. R.; Saffaro, F. A. 


\begin{tabular}{|c|c|c|c|c|c|c|c|}
\hline \multicolumn{4}{|c|}{ PRIMEIRA FASE DA LAJE } & \multicolumn{4}{|c|}{ SEGUNDA FASE DA LAJE } \\
\hline Dia & $\begin{array}{l}\text { Pacote de } \\
\text { trabalho }\end{array}$ & $\begin{array}{l}\text { Detalhamento do } \\
\text { pacote de trabalho }\end{array}$ & $\begin{array}{c}\mathbf{N}^{0} \text { de } \\
\text { operários }\end{array}$ & Dia & $\begin{array}{l}\text { Pacote de } \\
\text { trabalho }\end{array}$ & $\begin{array}{c}\text { Detalhamento do } \\
\text { pacote de } \\
\text { trabalho } \\
\end{array}$ & $\begin{array}{c}\mathbf{N}^{\circ} \text { de } \\
\text { operários }\end{array}$ \\
\hline \multirow{7}{*}{ 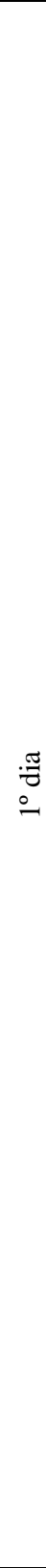 } & $\begin{array}{l}\text { Locação } 18 \\
\text { pilares (P15 ao } \\
\text { P32) }\end{array}$ & $\begin{array}{l}\text { - Locação gastalhos (1 } \\
\text { operário + encarregado) } \\
\text { - Fixação bases de } \\
\text { escoras para pilares (1 } \\
\text { operário) }\end{array}$ & \multirow{7}{*}{6} & \multirow{7}{*}{$\begin{array}{l}\text { ت7 } \\
\text { in }\end{array}$} & $\begin{array}{l}\text { Desforma } \\
\text { laje do } \\
\text { pavimento } \\
\text { inferior }\end{array}$ & & \multirow{7}{*}{11} \\
\hline & $\begin{array}{l}\text { Desforma } \\
\text { bordas }\end{array}$ & $\begin{array}{l}\text { - Desforma bordas } \\
\text { ( } 2 \text { operários) }\end{array}$ & & & $\begin{array}{l}\text { Montagem } \\
\text { escoramento } \\
\text { BKS (L3- } \\
\text { L4-L5) } \\
\end{array}$ & $\begin{array}{l}\text { - Montagem } \\
\text { cimbramento } \\
\text { (4 operários) }\end{array}$ & \\
\hline & $\begin{array}{l}\text { Posicionamento } \\
\text { plataformas de } \\
\text { periferia (4un) }\end{array}$ & $\begin{array}{l}\text { - Colocação plataformas } \\
\text { (4 operários) }\end{array}$ & & & $\begin{array}{l}\text { Assoalho e } \\
\text { formas } \\
\text { plásticas }\end{array}$ & $\begin{array}{l}\text { - Montagem } \\
\text { assoalho e } \\
\text { distribuição } \\
\text { formas plásticas } \\
\text { (4 operários) } \\
\text { - Transporte peças } \\
\text { do pavimento } \\
\text { inferior } \\
\text { ( } 3 \text { operários) - } \\
\text { - } 1 \text { operário da } \\
\text { produção de pré- } \\
\text { vigas vai para o } \\
\text { pavimento }\end{array}$ & \\
\hline & $\begin{array}{l}\text { Montagem } \\
\text { armadura de } 18 \\
\text { pilares (P15 ao } \\
\text { P32) }\end{array}$ & Armadores & & & $\begin{array}{l}\text { Armadura } \\
\text { laje }\end{array}$ & $\begin{array}{l}\text { - Armadores - } \\
\text { após } 12 \mathrm{~h} 00\end{array}$ & \\
\hline & $\begin{array}{l}\text { Montagem } \\
\text { formas de } 16 \\
\text { pilares (P17 ao } \\
\text { P32) }\end{array}$ & $\begin{array}{l}\text { - Colocação formas e } \\
\text { agulhas } \\
\text { (2 operários) } \\
\text { - Colocação escoras + } \\
\text { prumo + esquadro } \\
\text { (2 operários) } \\
\text { - Limpeza e aplicação } \\
\text { desmoldante } \\
\text { (2 operários) } \\
\end{array}$ & & & & & \\
\hline & $\begin{array}{l}\text { Posicionamento } \\
\text { pré-vigas ( } 4 \text { a } 9 \\
\text { un.) }\end{array}$ & $\begin{array}{l}\text { - Posicionamento } \\
\text { cabeça dos pilares (2 } \\
\text { operários) } \\
\text { - Posicionando escoras } \\
\text { ( } 2 \text { operários) } \\
\text { - Aferição esquadro } \\
\text { (2 operários) }\end{array}$ & & & & & \\
\hline & $\begin{array}{l}\text { Desforma laje } \\
\text { do pavimento } \\
\text { inferior }\end{array}$ & & & & & & \\
\hline
\end{tabular}

Quadro 3 - Visualização parcial da planilha do modelo TP3 


\begin{tabular}{|c|c|}
\hline $\begin{array}{l}\text { Elemento } \\
\text { conceitual }\end{array}$ & Especificações relacionadas \\
\hline \multirow[b]{2}{*}{ Meta } & Características do produto final conforme requisitos dos clientes \\
\hline & $\begin{array}{l}\text { Objetivos atrelados aos critérios competitivos valorizados pela organização } \\
\text { (prazo, custo) }\end{array}$ \\
\hline \multirow{3}{*}{ Restrições } & Compartilhamento de recursos (materiais, equipamentos e mão de obra) \\
\hline & Condições requeridas para uso de materiais e componentes \\
\hline & Quantidade padrão de estoque em processo \\
\hline \multirow{13}{*}{ Método } & Atividades constituintes do processo \\
\hline & Sequência técnica para as atividades \\
\hline & Pacotes de trabalho distribuídos ao longo do período delimitado pelo takt-time \\
\hline & Sequência para a execução das unidades de cada pacote de trabalho \\
\hline & Dimensionamento da equipe de produção \\
\hline & Designação da quantidade de operários para cada pacote de trabalho \\
\hline & Especificação de kits de recursos para cada pacote de trabalho \\
\hline & Especificações para transporte de materiais \\
\hline & Especificações para armazenagem de materiais \\
\hline & Ponto-chave \\
\hline & Rotina de operações para equipamentos \\
\hline & Pontos de inspeção de qualidade e as tolerâncias correspondentes \\
\hline & Pontos de monitoramento em relação à meta \\
\hline
\end{tabular}

Quadro 4 - Elementos constituintes do TP na construção civil

Com relação à meta, ficou evidente que sua explicitação é importante para o estabelecimento do TP, como citam Kondo (1991) e Campos (2004), uma vez que as demais especificações configuram-se em função da meta eleita como prioritária para a produção. No caso analisado, a meta referia-se a prazo. Por essa razão, a análise dos elementos do método esteve voltada à execução das tarefas no tempo de ciclo adequado ao takt-time.

Quanto às restrições, uma vez que elas foram definidas como aspectos que limitam o desempenho do sistema de produção, fica claro que a existência delas pode dificultar o alcance das metas. Por essa razão, devem ser consideradas cuidadosamente na definição do TP. Destaca-se que as restrições puderam ser identificadas na fase inicial do estudo, visto que existiam em decorrência das decisões tomadas pela empresa durante o planejamento do sistema de produção, tais como os tipos de equipamentos utilizados e como estes deveriam ser compartilhados entre as etapas da obra e o projeto de canteiro de obras. Essas decisões repercutiram, por exemplo, na necessidade da grua para a concretagem das prévigas na central de produção.

Com relação ao método, ficou evidente que ele deve conter especificações que conduzam ao entendimento de como o processo produtivo deve acontecer. Entre as especificações, destaca-se a identificação do conteúdo do trabalho, reforçando a citação de Ballard e Tommelein (1999), e da divisão desse conteúdo em pacotes de trabalho. O estabelecimento dos pacotes justifica-se pela necessidade de especificar a quantidade de atividades a executar em cada dia do ciclo de produção. Por exemplo, a atividade de montagem das lajes era executada em dois dias consecutivos. A divisão em pacotes deixava claramente definida a área de laje a ser executada em cada dia.

A quantificação dos recursos a utilizar no cumprimento das tarefas foi citada por Currie (1997) e por Ballard e Tommelein (1999) como relevante para a especificação de um processo. Essa importância foi reforçada nesta pesquisa, a partir da observação das dificuldades em abastecer os postos de trabalho na quantidade e tempo adequados, repercutindo na instabilidade no cumprimento dos pacotes. Essas dificuldades resultaram na especificação do kit de recursos.

O cumprimento dos pacotes era, também, fortemente influenciado pelo uso da grua, justificando a especificação da rotina de operações para esse equipamento. Da mesma forma, as definições sobre transporte e áreas de armazenagem também exerciam influência sobre a evolução da produção, reforçando a necessidade de definições sobre elas, como foi indicado por Currie (1997) e por Ballard e Tommelein (1999).

Os pontos-chave, como citado por Liker e Meier (2008), permitem ressaltar a necessidade de precisão nas atividades e conduzem à execução correta delas, garantindo 0 alcance das 
características de qualidade, tempo, custo e segurança previamente definidas para o produto.

\section{Conclusões}

O conteúdo do TP indicado no Quadro 4 reflete as especificações identificadas como importantes para a redução da variabilidade nos processos da construção civil, atendendo ao objetivo da pesquisa, voltado a identificar quais especificações deveriam compor o padrão para processos na construção. Ressalta-se que as especificações apontadas expressam os elementos conceituais do padrão encontrados na literatura consultada: meta, restrições e método.

As especificações identificadas contribuíram para disseminar um objetivo comum a ser perseguido por todos os envolvidos na produção e para reduzir a variabilidade no processamento (execução dos pacotes de trabalho) e no fluxo (alimentação dos pacotes e interação entre eles). A delimitação dos pacotes, a quantidade de operários designados aos mesmos e os pontos-chave contribuem para a estabilidade na execução de cada pacote. A variabilidade no fluxo é minimizada por meio de especificações como os kits de recursos, formas de transporte e armazenagem deles, rotina da grua e, também, estabilidade do pacote de trabalho anterior.

Nota-se que o conteúdo do TP para a construção civil é mais abrangente que aquele referenciado pela literatura do STP. Os kits de recursos, a rotina da grua e as definições sobre transporte e armazenagem são especificações adicionais exigidas pela configuração da produção na construção.

Diferenças também puderam ser constatadas quanto à rotina de operações padrão. Uma vez definidas as equipes responsáveis por cada pacote, a rotina foi estabelecida tendo essas equipes como foco, ou seja, não houve abordagem das ações do operário de forma individual, como relatado no STP. As equipes dispunham de autonomia para organizar-se no cumprimento das atividades de cada pacote, desde que odedecessem à sequência estabelecida e cumprissem a totalidade dos pacotes designados para cada dia. Esse aspecto ressalta a necessidade de avanços na pesquisa, investigando quais especificações relativas a cada pacote de trabalho são relevantes para atingir o cumprimento sistemático do tempo de ciclo e qualidade dos produtos.

Outro aspecto divergente em relação ao contexto do STP está associado à adaptação do conceito de takt-time. Constatou-se que, devido ao longo tempo de ciclo dos processos da construção, normalmente expressados em termos de horas ou dias, o elemento takt-time assume uma abordagem diferente da manufatura e não é diretamente utilizado como um parâmetro de controle para a evolução da produção. Haveria necessidade de estabelecer pontos de monitoramento relativos à execução de cada pacote, como forma de facilitar a identificação de desvios em relação ao tempo previsto no TP.

Em síntese, como resultado desta pesquisa, foi possível estabelecer uma discussão sobre a transferência do conceito de TP para o contexto da construção. A análise dessa transferência permitiu identificar um conjunto de especificações que contribuem para a evolução da produção na construção segundo regras previamente definidas, para alcançar os resultados almejados de forma sistemática. Dessa forma, o TP mostrou-se como uma ferramenta potencialmente eficaz para o gerenciamento do processo produtivo na construção, a partir das adaptações pertinentes.

\section{Referências}

ALVAREZ, R. R.; ANTUNES JUNIOR, J. A. V.

Takt-Time: conceitos e contextualização dentro do Sistema Toyota de Produção. Gestão \&

Produção, v. 8, n. 1, p. 1-18, 2001.

BALLARD. G. The Last Planner System of Production Control. Birminghan, 2000. Tese (Doutorado em Engenharia Civil) - School of Civil Engineering, University of Birminghan, Birminghan, 2000.

BALLARD, G.; HOWELL, G. Shielding Production: an essential step in production control. Journal of Construction Engineering and Management, Nova York, v. 124, n. 1, p. 11-17, 1998.

BALLARD, G.; TOMMELEIN, I. Aiming For

Continuous Flow: white paper 03. Lean Construction Institute, 1999. Disponível em: <http://www.leanconstruction.org $>$. Acesso em: 16 jun. 2011.

BARROS NETO, J. P. Proposta de Um Modelo de Formulação de Estratégias de Produção Para Pequenas Empresas de Construção Habitacional. Porto Alegre, 1999. Tese (Doutorado em Administração) - Programa de PósGraduação em Administração, Universidade Federal do Rio Grande do Sul, Porto Alegre, 1999. 
BULHÕES, I. R. Diretrizes Para Implementação de Fluxo Contínuo na Construção Civil: uma abordagem baseada na mentalidade enxuta. Campinas, 2009. Tese (Doutorado em Engenharia Civil) - Faculdade de Engenharia Civil, Arquitetura e Urbanismo, Universidade Estadual de Campinas, Campinas, 2009.

CAMPOS, V. F. TQC: controle da qualidade total no estilo japonês. 8. ed. Nova Lima: INDG Tecnologia e Serviços Ltda., 2004.

COELHO, H. O. Diretrizes e Requisitos Para o Planejamento e Controle da Produção em Nível de Médio Prazo na Construção Civil. $133 \mathrm{f}$. Porto Alegre, 2003. Dissertação (Mestrado em Engenharia Civil) - Núcleo Orientado para a Inovação da Edificação, Programa de PósGraduação em Engenharia Civil, Universidade Federal do Rio Grande do Sul, Porot Alegre, 2003.

CURRIE, R. M. Work study. $4^{\text {th }}$. Great Britain: A Pitman International Taxt, 1997.

DENNIS, P. Produção Lean Simplificada. 2. ed. Porto Alegre: Bookman, 2008.

GOLDRATT, E. M.; COX, J. F. A Meta: um processo de melhoria continua. São Paulo: Nobel, 2002.

IMAI, M. Kaizen: a estratégia para o sucesso competitivo. 6. ed. São Paulo: Instituto IMAM, 2005.

KONDO, Y. Human Motivation: a key factor for management. Tokyo: 3A Corp., 1991.

KOSKELA, L. Application of the New Production Philosophy To Construction. Technical Report, $n$. 72, 1992. 75 p.

LEAN INSTITUT BRASIL. Léxico Lean: glossário ilustrado para praticantes do pensamento lean. São Paulo: Lean Institute Brasil, 2003.

LIKER, J. K. O modelo Toyota: 14 princípios de gestão do maior fabricante do mundo. Porto Alegre: Bookman, 2005.

LIKER, J. K.; MEIER, D. O modelo Toyota: manual de aplicação. Porto Alegre: Bookman, 2007.
LIKER, J. K.; MEIER, D. P. O Talento Toyota: o modelo aplicado ao desenvolvimento de pessoas. Porto Alegre: Bookman, 2008.

MARTIN, T. D.; BELL, J. T. New Horizons in Standardized Work: techniques for manufacturing and business process improvement. New York: Productivity Press, 2011.

MONDEN, Y. Toyota Production System: an integrated approach to just-in-time. $3^{\mathrm{TH}}$. Norcross, GA: Industrial Engineering and Management Press, 1997.

OHNO, T. Sistema Toyota de Produção: além da produção em larga escala. Porto Alegre: Bookman, 1997.

PRODUCTIVITY PRESS DEVELOPMENTE

TEAM. Standard Work for the Shopfloor. New York: Productivity Press, 2002.

RITZMAN, L. P.; KRAJEWSKI, L. J.

Administração da Produção e Operações. São Paulo: Pearson Prentice Hall, 2004.

SHINGO, S. Sistemas de Produção Com Estoque Zero: o sistema Shingo para melhoria contínua. Porto Alegre: Bookman, 1996.

SPEAR, S.; BOWEN, H. K. Decoding the DNA of the Toyota Production System. Harvard Business Review, Boston, v. 77, n. 5, p. 96-106, sep./oct. 1999.

WHITMORE, T. Standardized Work.

Manufacturing Engineering, v. 140. n. 5, may 2008.

YIN, R. K. Estudo de Caso: planejamento e métodos. 2. ed. São Paulo: Bookman, 2001.

\section{Agradecimentos}

Agradecimentos à CAPES, pela bolsa de mestrado; à segunda autora, aos pesquisadores do Programa de Mestrado da Universidade Estadual de Londrina e à empresa construtora, pela permissão e colaboração no desenvolvimento da pesquisa.

\section{Revista Ambiente Construído}

Associação Nacional de Tecnologia do Ambiente Construído

Av. Osvaldo Aranha, 99 - 3o andar, Centro

Porto Alegre - RS - Brasil

CEP 90035-190

Telefone: +55 (51) 3308-4084

Fax: +55 (51) 3308-4054

www. seer. ufrgs. br/ ambienteconstruido

E-mail: ambienteconstruido@ufrgs.br

44 Fazinga, W. R.; Saffaro, F. A. 